Wolfgang Obergassel, Christof Arens, Lukas Hermwille,

Nicolas Kreibich, Hermann E. Ott, Hanna Wang-Helmreich

\title{
Paris Agreement: Ship Moves Out of the Drydock
}

An Assessment of COP24 in Katowice

Originally published in:

Carbon \& Climate Law Review, vol. 13, no. 1, pp. 3-18

DOI: $10.21552 / c c l r / 2019 / 1 / 4$ 
Wolfgang Obergassel $a$,

Christof Arens a

Lukas Hermwille $a, b$

Nicolas Kreibich a

Hermann E. Ott c

Hanna Wang-Helmreich a

\section{Paris Agreement: Ship Moves Out of the Drydock}

\section{An Assessment of COP24 in Katowice}

a Wuppertal Institute, Germany

b Vrije Universiteit, Amsterdam

c ClientEarth

* Corresponding author:

Wolfgang Obergassel

Wuppertal Institut für Klima, Umwelt, Energie gGmbH

Döppersberg 19

42103 Wuppertal

Germany

E-mail: wolfgang.obergassel@wupperinst.org

Phone: +49 2022492149

Fax: +492022492250

This is the author's version of a work that was accepted for publication. Changes resulting from the publishing process, such as editing, corrections and structural formatting, may not be reflected in this document. Changes may have been made to this work since it was submitted for publication. A definitive version was subsequently published in the Journal cited above. 


\title{
Paris Agreement: Ship Moves Out of the Drydock
}

\section{An Assessment of COP24 in Katowice}

Wolfgang Obergassel, Christof Arens, Lukas Hermwille, Nicolas Kreibich, Hermann E. Ott, Hanna Wang-Helmreich*

\begin{abstract}
Last year's conference of the global climate change regime took place from 2 until 15 December 2018 in Katowice, Poland. The conference had two main objectives: operationalising the Paris Agreement by adopting detailed rules for its implementation, and starting the process of strengthening Parties' climate protection contributions. This article covers the negotiations on these two sets of issues and also includes a discussion of other recent climate activities by Parties and nonParty actors.
\end{abstract}

Success of the negotiations in Katowice was far from assured, but in the end COP24 concluded with the adoption of the "Katowice Climate Package" setting out detailed guidelines on how to implement its various elements. However, the conference fell short on the first objective, none of the major emitting countries was ready to step up its climate ambition. The most important aspect of the Katowice outcome is therefore that it has brought the wrangling about implementation procedures to a close, making way for the true task at hand: the strengthening of national and international activities to protect the climate and the implementation of the existing pledges.

Arguably, a key factor that has been slowing down climate policy is the power of entrenched interests. The article therefore concludes with a reflection on how such barriers to climate action may be overcome and what role future COPs may play in this regard.

\section{Introduction}

Last year's conference of the global climate change regime took place from 2-15 December 2018 in Katowice, Poland. It included the 24th Conference of the Parties (COP24) to the UN Framework Convention on Climate Change (UNFCCC), the $14^{\text {th }}$ Conference of the Parties serving as the Meeting of the Parties to the Kyoto Protocol (CMP14), the resumed first Conference of the Parties serving as the Meeting of the Parties to the Paris Agreement (CMA1), and their subsidiary bodies. The conference had two main objectives: operationalizing the Paris Agreement by adopting

\footnotetext{
*Wolfgang Obergassel, Co-Head of Research Unit, Wuppertal Institute; Christof Arens, Project Co-Ordinator, Wuppertal Institute; Lukas Hermwille, Project Co-Ordinator, Wuppertal Institute; Nicolas Kreibich, Research Fellow, Wuppertal Institute; Hermann E. Ott, Head of German office, Client Earth; Hanna Wang-Helmreich, Research Fellow, Wuppertal Institute. For correspondence: Wolfgang Obergassel <wolfgang.obergassel@wupperinst.org>, Christof Arens <christof.arens@wupperinst.org>, Lukas Hermwille <lukas.hermwille@wupperinst.org>, Nicolas Kreibich <nico.kreibich@wupperinst.org>, Hermann E. Ott <HOtt@clientearth.org>, Hanna Wang-Helmreich <hanna.wanghelmreich@wupperinst.org>.
} 
detailed rules for its implementation, and starting the process of strengthening Parties' climate protection contributions.

The year 2018 provided ample evidence that global climate change is already here: Devastating extreme heat and unprecedented drought in large parts of North America and Europe, wildfires in California and Scandinavia, severe floods in East Africa, rare tropical cyclones in Somalia, Djibouti, Yemen and Oman, and a record breaking tropical cyclone season. At the same time, scientific knowledge about the impacts of climate change and the options to avoid the worst impacts was never more prominent. A special report by the Intergovernmental Panel on Climate Change (IPCC) ${ }^{1}$ and the latest edition of UN Environment's annual emission gap report ${ }^{2}$ reiterated that the contributions countries have so far pledged are far away from what would be necessary to achieve the objectives of the Paris Agreement. While the Agreement has the aim to keep global temperature increase compared to pre-industrial levels well below $2^{\circ} \mathrm{C}$ and to make best efforts to stay below $1.5^{\circ} \mathrm{C}$, current pledges would lead to a warming of $3-4^{\circ} \mathrm{C}$ by the end of this century. Global emissions are continuing to rise, with 2018 marking a new record year.

In this context, many had hoped that the conclusion of the "Talanoa Dialogue", a process to identify options for enhanced mitigation ambition (see more below), would bear fruit already in Katowice. However, none of the major emitting countries was ready to step up. Climate ambition, it seems, is desperately lacking in the capitals of the world, not to mention those places like the United States and Brazil where nationalist governments have started to roll back even the existing insufficient level of climate action. The atmosphere in Katowice was further marred by the heavy crackdown by the host nation's government on civil society activists.

Against this backdrop, to the surprise of many, COP24 concluded late on 15 December 2018 with the adoption of the "Katowice Climate Package". ${ }^{3}$ This set of decisions operationalizes the 2015 Paris Agreement by setting out detailed guidelines on how to implement its various elements, in particular how countries are to develop and report on their nationally determined contributions (NDCs), that is, their pledges for how they will contribute to combating climate change. Other key elements are financial support for developing countries and the procedures for conducting the first 'Global Stocktake' for assessing the effectiveness of global climate action in 2023.

These guidelines are more robust than many had dared to expect at the start of the conference. Nonetheless, their adoption is no more than a step in the right direction. The most important aspect of the Katowice outcome is therefore that it has brought the wrangling about implementation procedures largely to a close, making way for the true task at hand: the strengthening of national and international activities to protect the climate and the implementation of the existing pledges.

\section{More Speed Required - Raising Ambition}

The Paris outcome requires the Parties to the Paris Agreement to produce new or updated contributions by 2020. Given the lack of climate ambition most countries have shown so far, the

\footnotetext{
${ }^{1}$ IPCC, 'Special Report. Global Warming of $1.5^{\circ} \mathrm{C}$. An IPCC special report on the impacts of global warming of $1.5^{\circ} \mathrm{C}$ above pre-industrial levels and related global greenhouse gas emission pathways, in the context of strengthening the global response to the threat of climate change, sustainable development, and efforts to eradicate poverty (Intergovernmental Panel on Climate Change, 2018) <https://www.ipcc.ch/sr15/> accessed 25 March 2019

2 UNEP, The Emissions Gap Report 2018 (United Nations Environment Programme 2018)

3 UNFCCC, 'Katowice Climate Change Conference - December 2018', (United Nations Framework Convention on Climate Change, n.d.) <https://unfccc.int/katowice> accessed 25 March 2019
} 
question in Katowice was whether the conference would send a strong signal on the need for all countries to strengthen their contributions. While Article 4.3 of the Paris Agreement mandates that NDCs should reflect a Party's "highest possible ambition", many Parties disputed that the 2020 round of re-submitting NDCs entailed a requirement to increase ambition.

To inform the process until 2020, Parties conducted the so-called 'Talanoa Dialogue' parallel to the formal diplomatic negotiations over the course of 2018. 'Talanoa' is a concept introduced by the Fijian presidency of the 2017 climate conference and denotes an open sharing of views. The process ultimately concluded in Katowice with the 'Talanoa Call for Action', which calls upon all countries and stakeholders to act with urgency. ${ }^{4}$ The process also produced a synthesis report of all the inputs received and discussions held over the course of the year. ${ }^{5}$

One key input to the Talanoa Dialogue was the IPCC's special report on the $1.5^{\circ} \mathrm{C}$ warming limit laid down in the Paris Agreement. The report concludes that "every bit of warming matters", as IPCC representatives explained at the conference. Whether global warming is kept below $1.5^{\circ} \mathrm{C}$ or only below $2^{\circ} \mathrm{C}$ will make a huge difference for humans and ecosystems. In addition, the report assesses emission pathways for achieving these temperature limits. To maintain a good chance of staying below $1,5^{\circ} \mathrm{C}$, global emissions will essentially need to be halved by 2030 and be reduced to net zero by 2050 .

However, the USA, Saudi Arabia, Russia and Kuwait caused substantial delays and aggravation by refusing to adopt a decision with language to "welcome" the report. Saudi Arabia argued that they could not welcome the report as it contained substantial open questions and uncertainties. Ultimately, Parties resolved to welcome the report's "timely completion" and "invited" countries to make use of the report in their further work. However, the decision also "recognises the role of the IPCC in providing scientific input to inform Parties in strengthening the global response to the threat of climate change" and refers to the special report as "reflecting the best available science." ${ }^{\prime}$ On the whole, the decision therefore confirms the status of the IPCC and the special report.

As the Talanoa Dialogue ran in parallel to the diplomatic negotiations, the question was how its outcome would be reflected in the formal conference decisions. In this regard, instead of a strong call to increase ambition, delegates decided to merely "take note" of the dialogue's outcome, input and outputs, and to invite Parties "to consider the outcome, inputs and outputs of the Talanoa Dialogue in preparing their nationally determined contributions and in their efforts to enhance pre-2020 implementation and ambition".7 This non-committal language is compensated to some extent by other parts of the decision, which reaffirm the need for ambitious efforts to achieve the objectives of the Paris Agreement and stress the urgency of enhancing ambition. ${ }^{8}$ In addition, the decision refers to the special summit the UN Secretary-General is convening in 2019 as a place for demonstrating enhanced ambition. Almost comical, though, is the formulation that Parties

\footnotetext{
${ }^{4}$ UNFCCC, 'Announcement, Join the Talanoa Call for Action' (United Nations Framework Convention on Climate Change, 12 December 2018) <https://unfccc.int/news/join-the-talanoa-call-for-action> accessed 25 March 2019

5 'Talanoa Dialogue for Climate Ambition, Synthesis of the Preparatory Phase, 19/11/2018' <https://img1.wsimg.com/blobby/go/9fc76f74-a749-4eec-9a06-5907e013dbc9/downloads/1cu4u95lo_238771.pdf> accessed 25 March 2019

${ }^{6}$ UNFCCC 'Decision 1/CP.24, Preparations for the implementation of the Paris Agreement and the first session of the Conference of the Parties serving as the meeting of the Parties to the Paris Agreement' UN Doc FCCC/CP/2018/10/Add.1 (Advance version 19 March 2019) paras 24-28

${ }^{7}$ ibid paras $35-37$

8 ibid para 14
} 
demonstrate their ambition already through their participation in that event. ${ }^{9}$ Parties need to do their homework first.

COP24 thus clearly failed in its task to urgently call on Parties to increase their mitigation ambition. In terms of public messages, however, the "media tsunami" created by the controversy on whether or not to "welcome" the IPCC report may have compensated for the lack of strong language in the COP decision. ${ }^{10}$

\section{Moving Paris out of the Drydock - The Rulebook}

The Paris Agreement established the objectives and basic mechanisms of international climate policy for the time after 2020, but still required more detailed technical rules on how to implement its various aspects, e.g. on how Parties are supposed to report on the actual realisation of their contributions in order to ensure comparability of the various efforts made. The Paris conference had established a work programme to develop these rules, which the Katowice conference was supposed to finish. Despite three years of negotiations, delegates arrived in Katowice with many unresolved issues, embodied in 236 pages of texts that included many alternative options and nearly 3,000 square brackets indicating areas of disagreement. ${ }^{11}$ Whether it would be possible to reduce the number of brackets and options to zero was very much an open question. Divisions were still sharp at the end of the first week and UN SecretaryGeneral Guterres himself was engaged three times on site to help bridge the divides. Once again, the key cross-cutting issue was differentiation: whether the same rules should apply to all Parties, or whether different rules should apply to the traditional groups of "developed" and "developing" countries.

\section{Rowing Instructions - The NDC Guidelines}

One of the key elements of the implementation guidelines of the Paris Agreement are further specifications with respect to the key vehicle of climate action: the nationally determined contributions (NDCs) that Parties have to revise or update regularly to communicate their climate action targets and policies. In the run-up to the Paris conference, Parties had failed to agree on a common format and information requirements for what were then still "intended" NDCs. ${ }^{12}$ As result, there is a broad range of different types of NDCs and the information provided in the NDCs is hardly comparable. To address this issue, Parties had requested the Ad Hoc Working Group on the Paris Agreement (APA) to develop guidance for the information to be provided by Parties to facilitate clarity, transparency and understanding of NDCs as well as guidance for the accounting of NDCs. ${ }^{13}$

\footnotetext{
9 ibid paras 49 f.

10 Jennifer Iris Allan, Beate Antonich, Jennifer Bansard, Katherine Browne, Natalie Jones and Mari Luomi, 'Summary of the Katowice Climate Change Conference: 2-15 December 2018' (2018) 12(747) ENB <http://enb.iisd.org/vol12/enb12747e.html> accessed 25 March 2019

11 Simon Evans and Jocelyn Timperley, 'COP24: Key outcomes agreed at the UN climate talks in Katowice' (Carbon Brief, 16 December 2018) <https://www.carbonbrief.org/cop24-key-outcomes-agreed-at-the-un-climate-talks-in-katowice> accessed 25 March 2019

${ }^{12}$ Wolfgang Sterk, Christof Arens, Nicolas Kreibich, Lukas Hermwille Florian Mersmann and Timon Wehnert, Warsaw Groundhog Days - Old Friends, Positions and Impasses Revisited All Over Again at the 2013 Warsaw Climate Conference (Wuppertal Institute for Climate, Environment and Energy 2013) <http://wupperinst.org/en/info/details/wi/a/s/ad/2447/> accessed 21 March 2019

${ }^{13}$ UNFCCC 'Decision 1/CP.21, Adoption of the Paris Agreement' UN Doc FCCC/CP/2015/10/Add.1 (29 January 2016) paras 28 and 31 respectively
} 
In correspondence with the first mandate Parties agreed to a list of information requirements that will be only applicable for the second round NDCs, but Parties are also "strongly encouraged" to apply them for updates of the first NDCs that are taking effect as of $2020 .^{14}$ The information requirements include:

- information on the reference point of the target;

- timeframe and implementation period;

- the scope (what gases and what sectors are covered?);

- the planning process;

- assumptions and methodologies;

- considerations of how the NDC is fair and ambitious;

- and how the NDC contributes to the long-term goals of the Paris Agreement.

Especially noteworthy is that countries are obligated to explain their rationale of why they consider their contribution equitable. This is particularly relevant because many of the current NDCs fail to meet the required ambition - no matter what kind of equity rationale is applied. ${ }^{15}$ Notable is also what ultimately was not agreed: earlier drafts included also information requirements on adaptation, finance, technology, and capacity building. Many developing countries had demanded that the NDCs should be "full scope" and cover all of these elements, while developed countries had argued that the NDCs should focus on mitigation. While these elements are not excluded from the NDCs, there is also no requirement to include these aspects in the next NDCs.

The second task was to provide guidelines for Parties on how to report progress on the implementation of NDCs (also see Transparency Framework). ${ }^{16}$ Of course, the first task - to properly define contributions - is essential for tracking progress. On that basis, Parties are now required to follow IPCC guidelines for accounting GHG emissions or explicate their methodology if they have opted for targets that cannot be assessed with existing IPCC approved methodologies.

The NDC guidelines will not do away with the fact that the world will continue to compare apples and oranges as countries will most likely continue to express their climate ambitions in very different metrics. Yet the guidelines adopted in Katowice will enable us to much better understand each individual piece of fruit.

\section{Planning for Heavy Weather - Adaptation Communication}

According to the Paris Agreement, Parties "should (...) submit and update periodically an adaptation communication, which may include its priorities, implementation and support needs, plans and actions". ${ }^{17}$ Adaptation communications are not only to increase the visibility and profile of adaptation, but also to strengthen adaptation action and support for developing countries, enhance learning and understanding of adaptation needs and actions, and provide

\footnotetext{
${ }^{14}$ UNFCCC 'Decision 4/CMA.1, Further guidance in relation to the mitigation section of decision 1/CP.21, Annex I, Information to facilitate clarity, transparency and understanding of nationally determined contributions, referred to in decision $1 / \mathrm{CP} .21$ ' UN Doc FCCC//PA/CMA/2018/3/Add.1 (Advance version 19 March 2019) para. 28

${ }^{15}$ See for example the assessments in the Climate Action Tracker, <https://climateactiontracker.org> accessed 21 March 2019

${ }^{16}$ UNFCCC 'Decision 4/CMA.1, Further guidance in relation to the mitigation section of decision 1/CP.21, Annex II, Accounting for Parties' nationally determined contributions, referred to in decision 1/CP.21' UN Doc FCCC//PA/CMA/2018/3/Add.1 (Advance version 19 March 2019) para 31

${ }^{17}$ Paris Agreement (adopted 12 December 2015, entered into force 4 November 2016) 55 ILM 740 Art 7.10
} 
input to the Global Stocktake (see below). Guidance on adaptation communications allows for a better understanding and options for aggregation of information on plans and progress in global adaptation efforts. While COP 21 had not provided a mandate to develop guidance for adaptation communications, Parties agreed to add guidance on adaptation communication to the APA agenda and the development of modalities and procedures for the adaptation registry to the Subsidiary Body for Implementation (SBI)'s agenda at APA 1 in May 2016. Both items became part of the work programme under the Paris Agreement at COP 22.

In Katowice, one of the discussions focused on the purpose and principles for the guidance. While several developing countries wanted the guidance to include the principle of common but differentiated responsibilities and respective capabilities (CBDR-RC), providing differentiation of guidance for developing and industrialised countries' adaptation communications, developed countries opposed. ${ }^{18}$ The final text does not differentiate guidance for the content of adaptation communications. Application of the guidance is voluntary, however, and Parties decided that adaptation communication is "country-driven and flexible, including in the choice of communication or document". ${ }^{19}$ Adaptation communications shall not impose any additional burden on developing country Parties, nor be used for country comparisons, nor be subject to a review. In its final decision, the CMA invited Parties to provide in their adaptation communication information on elements such as national circumstances, adaptation priorities, strategies, policies, plans, goals and action as well as, inter alia, support needs, and implementation of adaptation actions and plans. ${ }^{20}$

Following corresponding suggestions by developing country Parties, the CMA finally decided to take stock of, and if necessary, revise the guidance on adaptation communications at CMA 8 $(2025) \cdot{ }^{21}$

Adaptation communications shall be recorded in a public registry together with the public registry for NDCs managed by the Secretariat. ${ }^{22}$

While the guidance for adaptation communications outlines a common structure, application of the guidance is voluntary, leaving it up to every country how to report on progress achieved and the gaps remaining. Depending on the structure countries will finally choose for their adaptation communications, this may well complicate the UNFCCC Secretariat's efforts to provide an overview of adaptation communications and aggregate information. Nevertheless, adoption of the guidance is an important milestone for achieving adaptation goals, including required climate finance.

\section{Logging Progress - The Transparency Framework}

The "Enhanced Transparency Framework for Action and Support" can be considered a cornerstone of the Paris Agreement. It sets the rules by which countries are to report on their

\footnotetext{
${ }^{18}$ Allan et al. 'Summary' (n. 10).

${ }^{19}$ UNFCCC 'Decision 9/CMA.1, Further guidance in relation to the adaptation communication, including, inter alia, as a component of nationally determined contributions, referred to in Article 7, paragraphs 10 and 11, of the Paris Agreement' UN Doc FCCC/PA/CMA/2018/3/Add.1 (Advance version) 19 March 2019) para 2

20 ibid. Annex

21 ibid. para 16

22 ibid., para 5; see also UNFCCC 'Decision 10/CMA.1, Modalities and procedures for the operation and use of a public registry referred to in Article 7, paragraph 12, of the Paris Agreement' UN Doc FCCC/PA/CMA/2018/3/Add.1 (Advance version 19 March 2019) para 3
} 
GHG emissions and progress towards implementing their NDCs, and it establishes international processes to review and assess the reports. While basic provisions had been agreed in Paris, Parties had requested the APA to develop recommendations for common modalities, procedures and guidelines with a view to adoption by the CMA at its first session. ${ }^{23}$

In Katowice, the key question was how to establish a reporting system for all Parties while at the same time providing flexibility to developing countries with capacity constraints. This question of differentiation clearly separated developed countries from the larger emerging economies: China and some other developing countries pushed for a system with separate reporting rules for developing and developed countries, striving for a continuation of the current reporting system under the Convention. The United States and other developed Parties, in contrast, envisaged a system with common reporting rules for all Parties with only limited flexibility for developing countries.

It was only after very intense negotiations and a move by China abandoning its previous stance that Parties in Katowice succeeded in overcoming the "bifurcation" of the existing reporting system and introduced common reporting rules applicable to all countries. Establishing a uniform reporting system had been one of the key priorities for the negotiators from the United States. Despite President Trump's announcement to withdraw from the Paris Agreement, US diplomats maintained their strong position. ${ }^{24}$ Ultimately, Parties reached a compromise by making flexibility provisions for developing countries with limited capacities operational, a concept that had already been introduced with the Paris Agreement.

The agreed modalities, procedures and guidelines ${ }^{25}$ for the Transparency Framework supersede the existing UNFCCC transparency system for Parties to the Paris Agreement. They require all countries from 2024 onwards to biennially submit greenhouse gas inventories, provide information on the progress towards meeting their NDC as well as other types of information. Notably, Parties will also have to report on potential transfers of mitigation outcomes and how these transfers are accounted for. These minimum requirements are to safeguard the environmental integrity of market-based cooperation under Article 6 (see section 5 below).

When submitting this information, developing countries with limited capacities are allowed to deviate from the uniform rules in specific areas. The application of this flexibility may relate to the scope, frequency and level of detail for reporting and is to be self-determined. Countries deviating from the uniform rules are required to indicate relevant capacity constraints as well as the time needed for overcoming the barriers encountered. However, contrary to what the US had demanded there is no firm time limit on this flexibility.

While the focus of the Transparency Framework is climate change mitigation, it also gathers information relevant for the areas of climate change impacts and adaptation, which is to be submitted by Parties on a non-mandatory basis. In addition to this reporting on climate action, the Transparency Framework compiles information on support for addressing climate change

\footnotetext{
${ }^{23}$ UNFCCC 'Decision 1/CP.21' (n. 13) para 91 and Paris Agreement (n. 17) Art. 13.13

24 Jeff Godell, 'Saving the Paris Agreement, How a team of U.S. diplomats helped salvage the global pact on climate change in the face of Trump's denialism' (Rolling Stone, 18 January 2019) <https://www.rollingstone.com/politics/politicsfeatures/saving-the-paris-agreement-780473/> accessed 15 March 2019

${ }^{25}$ UNFCCC 'Decision 18/CMA.1, Modalities, procedures and guidelines for the transparency framework for action and support referred to in Article 13 of the Paris Agreement, Annex, Modalities, procedures and guidelines for the transparency framework for action and support referred to in Article 13 of the Paris Agreement' UN Doc FCCC//PA/CMA/2018/3/Add.2 (Advance version 19 March 2019)
} 
and its impacts, such as financial support. With regard to financial support provided, only developed countries are required to submit such information. Similarly, information on support needed and received by developing countries is only gathered on a non-mandatory basis.

Parties in Katowice also agreed on how, when and by whom the information biennially provided by Parties is to be reviewed and assessed. Two processes have been detailed: In the technical expert reviews the consistency of the reports is checked against the provisions of the Transparency Framework and areas of improvement are highlighted. In line with the bottom-up spirit of the Paris Agreement, assessing the appropriateness of a Party's NDC and the adequacy of domestic actions, however, are explicitly not within the mandate of these reviews. A second process is the facilitative, multilateral consideration of progress, in which Parties exchange questions and answers in both writing and in a workshop format. This process is modelled after the multilateral assessments of the biennial reports from developed countries and the facilitative sharing of views on the biennial update reports from developing countries that exist under the pre-Paris transparency framework.

\section{The Pacemaker - The Global Stocktake}

In order to comply with the aim to keep global temperature increase well below $2^{\circ} \mathrm{C}$ and to make best efforts to stay below $1.5^{\circ} \mathrm{C}$, Parties need to urgently ramp up their mitigation ambition. In this regard, the Global Stocktake is key - it is supposed to serve as a catalyst for increasing ambition over time. As of 2023, this process will periodically (every 5 years) assess collective progress of the Parties towards the goals of the agreement. This assessment, in turn, is supposed to inform national governments in developing their subsequent NDCs. ${ }^{26}$

As requested 27 in the decisions to give effect to the Paris Agreement, Parties adopted modalities for the Global Stocktake in Katowice. These modalities now foresee three phases ${ }^{28}$ : information collection and preparation, technical assessment and a political phase of the "consideration of outputs". The work will focus on three "thematic areas" - mitigation, adaptation, and means of implementation and support. Notably and after substantial controversies, Parties agreed to open the process to also consider loss and damage associated with the adverse effects of climate change.

Critically discussed was furthermore the question of how equity considerations are to be reflected in the Global Stocktake. Article 14.1 of the Paris Agreement stipulates that the Global Stocktake be conducted in the light of equity and the reference to equity usually refers to the principle of differentiated responsibilities. References to equity now also feature prominently at various paragraphs of the corresponding modalities for the Global Stocktake. But what is still missing is a concrete idea of how a consideration of equity could be operationalized in practice.

Another major bone of contention was whether and to what degree the Global Stocktake is open to non-party stakeholders, observers and the public. On that matter, Parties decided that the Global Stocktake will be "conducted in a transparent manner and with the participation of non-

\footnotetext{
${ }^{26}$ For a detailed analysis of the elements required for the Global Stocktake to fully unfold its catalytic potential see Lukas Hermwille and Anne Siemons. What Makes an Ideal Global Stocktake? A Functional Analysis, Discussion Paper 22/2018 (Umweltbundesamt 2018) <http://www.umweltbundesamt.de/publikationen/what-makes-an-ideal-global-stocktake-afunctional> accessed 21 March 2019

27 UNFCCC 'Decision 1/CP.21' (n. 13) para 101

28 UNFCCC 'Decision 19/CMA.1, Matters relating to Article 14 of the Paris Agreement and paragraphs 99-101 of decision 1/CP.21' UN Doc FCCC//PA/CMA/2018/3/Add.2 (Advance version 19 March 2019)
} 
Party stakeholders" ${ }^{29}$ Opportunities for participation include to provide written submissions as input to the Global Stocktake and to participate in the technical dialogue that is supposed to be undertaken by means of "in-session round tables, workshops or other activities." 30 The extent to which non-Party stakeholders can actively participate, though, will be dependent on how the two co-facilitators choose to organize the technical dialogue.

There were, however, also worrying aspects concerning the participation of stakeholders. The decision specifies that the inputs will be made "fully accessible by Parties" (emphasis added) ${ }^{31}$. While this formulation does not explicitly exclude that the inputs will be publicly available, the phrase still caused some concern among observers that the Global Stocktake could end up being a rather secretive endeavour. This, of course, would contradict the purpose of the Global Stocktake: to foster a constructive debate on ambitious climate action and to (re)align national political agendas for the subsequent NDCs with the goals of the Paris Agreement. To this end, inclusive and extensive stakeholder engagement is absolutely essential.

\section{Rowing Together - Cooperation under Article 6}

Article 6.1 of the Paris Agreement recognizes "that some Parties choose to pursue voluntary cooperation in the implementation of their nationally determined contributions to allow for higher ambition in their mitigation and adaptation actions and to promote sustainable development and environmental integrity."

Article 6 subsequently establishes three approaches for countries to cooperate with each other:

- First, Articles 6.2 and 6.3 provide the option for Parties to directly engage in "cooperative approaches" and to use "internationally transferred mitigation outcomes" (ITMOs) in achieving their NDCs. International supervision of these cooperative activities is not foreseen, there will only be guidance for Parties that want to engage in cooperative approaches.

- Second, Articles 6.4-6.7 establish a new mechanism "to contribute to the mitigation of greenhouse gas emissions and support sustainable development". In contrast to the cooperative approaches, this mechanism will be supervised by a body designated by the Conference of the Parties serving as the Meeting of the Parties to the Paris Agreement (CMA). In addition, the Parties are to adopt rules, modalities and procedures (RMP) which must be observed when implementing activities under Article 6.4.

- Third, Articles 6.8 and 6.9 provide for the use of non-market approaches. Just how these approaches will work is to be determined with the development of a "framework for nonmarket approaches".

Parties in Paris had requested the Subsidiary Body for Scientific and Technological Advice (SBSTA) to advance these instruments by developing the guidance for Article 6.2, the rules, modalities and procedures for Article 6.4 and a draft decision on the work programme for Article 6.8. All three outcomes were to be adopted by the CMA at its first session. ${ }^{32}$

\footnotetext{
${ }^{29}$ ibid para 10

30 ibid. para 6

31 ibid. paras 10 and 21

${ }^{32}$ UNFCCC 'Decision 1/CP.21’ (n. 13) paras 36-40
} 
Negotiations at COP 24 started optimistically when the Independent Alliance of Latin America and the Caribbean (AILAC), ${ }^{33}$ Australia, Canada, the European Union, Japan, Mexico, New Zealand and Switzerland submitted a joint proposal on the need for corresponding adjustments when transferring mitigation outcomes under Article 6. These adjustments are in the view of many both scholars ${ }^{34}$ and Parties - a necessary precondition for robust accounting and for avoiding any kind of double counting.

Yet this momentum did not last long. At the beginning of week two, Parties had covered numerous issues regarding guidance for the cooperative approaches in Art. 6.2 as well as elements for the rules, modalities and procedures of the mechanism according to Art. 6.4. However, the text was full of options and brackets. Moreover, as had already become clear in the Bangkok session some months earlier, a substantial number of technical questions would need to be resolved the following year.

Towards the end of the conference, it became clear that the issue of corresponding adjustments could become a deal breaker. Mainly Brazil, but also the Arab Group strongly and continuously opposed respective language on safeguarding environmental integrity and transparent reporting. Yet the absence of corresponding adjustments would not only have created accounting loopholes for the Paris Agreement, it could also have led to double counting of mitigation outcomes authorized by Parties for use towards fulfilling other international mitigation obligations, e.g. under the International Civil Aviation Organization.

Despite compromise proposals by the Presidency, the controversies lasted well into the last day plus one of the conference. When still no common ground could be found, the complete text was taken back on Saturday afternoon and the Art. 6 rulebook decisions were deferred in their entirety to future sessions. The CMA called upon SBSTA to build negotiations on different text versions used in Katowice in order to finalize deliberations by COP 25 in 2019. ${ }^{35}$

However, within the Transparency Framework (Art. 13 of the PA), Parties were able to agree on minimum requirements to safeguard environmental integrity of Art. 6 transfers: the respective decision ${ }^{36}$ requires all Parties that would like to transfer mitigation outcomes to report on corresponding adjustments of their NDC, no matter if used towards an NDC or for purposes other than achievement of NDCs. The latter refers to schemes like the Carbon Offsetting and Reduction Scheme for International Aviation (CORSIA) established by the International Civic Aviation Organisation, which plans to use, inter alia, credits generated under Art. 6 of the Paris Agreement. Further reporting requirements for Art. 13 comprise information on sustainable development promotion, environmental integrity and transparency.

As a result, integrity risks associated with double counting were successfully hedged, while detailed decisions on how to govern the PA's Article 6 were shelved for 2019.

\footnotetext{
${ }^{33}$ The Independent Alliance of Latin America and the Caribbean is a Party group established in December 2012 during the Conference of the Parties in Doha, Qatar. It comprises the following countries: Chile, Colombia, Costa Rica, Guatemala, Honduras, Panama, Paraguay and Peru

${ }^{34}$ See, inter alia, Nicolas Kreibich and Lukas Hermwille, Robust Transfers of Mitigation Outcomes - Understanding Environmental Integrity Challenges (Wuppertal Institute for Climate, Environment, Energy 2016); Michael Lazarus, Anja Kollmuss and Lambert Schneider, Single-Year Mitigation Targets: Uncharted Territory for Emissions Trading and Unit Transfers (Stockholm Environment Institute 2014); Lambert Schneider, Anja Kollmuss and Michael Lazarus, Addressing the Risk of Double Counting Emission Reductions under the UNFCCC (Stockholm Environment Institute 2014)

${ }^{35}$ UNFCCC 'Decision 8/CMA.1, Matters relating to Article 6 of the Paris Agreement and paragraphs $36-40$ of decision 1/CP.21' UN Doc FCCC//PA/CMA/2018/3/Add.2 (Advance version 19 March 2019) paras 1-2.

${ }^{36}$ UNFCCC 'Decision 18/CMA.1' (n. 25) para 77 (d).
} 


\section{Dealing with Weak Performance - Implementation and Compliance}

Article 15.1 of the Paris Agreement establishes a mechanism to facilitate implementation of and promote compliance with its provisions. Article 15.2 furthermore stipulates that this mechanism "shall consist of a committee that shall be expert-based and facilitative in nature and function in a manner that is transparent, non-adversarial and non-punitive." In the decision adopting the Paris Agreement, Parties requested the APA to develop modalities and procedures for the effective operation of this committee. ${ }^{37}$

According to the modalities and procedures adopted in Katowice, ${ }^{38}$ the Committee will consist of 12 members with two of them drawn from each of the five geographical regions plus one from the small island developing states and one from least developed countries. The procedure is the result of many compromises: on the one hand, it is of a facilitative nature, emphasizing support and co-operation and without providing any punitive or forcible measures to the Committee. On the other hand, the procedure can be triggered by the Committee itself without the consent of the Party concerned in cases where a country fails to comply with binding information requirements. In other cases, for example if information provided appears to be inconsistent, the Committee will only be able to commence proceedings with the consent of the respective Party.

Interesting from a legal point of view, the procedure deviates from the general consensus requirement in the climate regime in that it allows for decisions to be taken by a three-fourths majority of members present and voting if all efforts to reach consensus have been exhausted. Measures that can be imposed are not punitive and confined to providing advice, assisting in the appropriation of financial support or the recommendation to develop an action plan. The Committee may also on its own provide recommendations regarding issues of a "systemic nature", thus providing it with a truly advisory role. And finally, the Committee may seek and receive information from processes, bodies, arrangements and forums under or serving the Paris Agreement.

\section{Building Team Capacity - Support for the Global South}

\section{Finance}

Financial support for developing countries' climate action has been a hotly contested issue for years. Crucial questions include not only the level of support, but also the definition of what constitutes climate financing and how both the level of resources provided by developed countries and their use in developing countries should be reported. Following the respective mandate given in Paris, ${ }^{39}$ a process to identify the respective information to be provided by Parties was initiated at COP 22.40

While finance had been a crucial bone of contention in earlier sessions, negotiations on this issue in Katowice progressed rapidly. As expected, the final text only includes relatively permissive rules, providing developed countries with great flexibility on what and how to report on climate

\footnotetext{
${ }^{37}$ UNFCCC 'Decision 1/CP.21' (n. 13) para 103

${ }^{38}$ Decision '20/CMA.1, Modalities and procedures for the effective operation of the committee to facilitate implementation and promote compliance referred to in Article 15, paragraph 2, of the Paris Agreement', UN Doc FCCC//PA/CMA/2018/3/Add.2 (Advance version 19 March 2019)

39 UNFCCC 'Decision 1/CP.21' (n. 13) para 55

40 UNFCCC 'Decision 13/CP.22, Initiation of a process to identify the information to be provided by Parties in accordance with Article 9, paragraph 5, of the Paris Agreement. UN Doc FCCC/CP/2016/10/Add.1 (31 January 2017)
} 
finance: Developed country Parties shall biennially communicate indicative quantitative and qualitative information on, inter alia, projected levels of public financial resources to be provided to developing country Parties. Other Parties providing resources are encouraged to do so on a voluntary basis. ${ }^{41}$

Countries may not only report grants, equity and guarantees as climate finance, but also concessional and non-concessional loans. Reporting of grant-equivalent values remains voluntary. This provides great leeway for developed countries on accounting of financial support. Furthermore, the final decision does not require climate finance to be new and additional, but only asks countries to provide information of what new and additional financial resources have been provided. Synthesis reports, workshops, and ministerial meetings will evaluate finance information and their sufficiency. ${ }^{42}$

One year earlier, at COP23 in Bonn, an important decision on the future architecture of international climate financing had been taken: The Adaptation Fund, originally set up under the Kyoto Protocol, will come under the umbrella of the Paris Agreement in the future. This means that the continued existence of this important fund is secured in the future. As the proceeds from the Clean Development Mechanism (CDM) have all but come to a standstill, the Adaptation Fund has had to rely on voluntary contributions from developed countries for years. In Katowice, Parties decided that the Adaptation Fund shall be financed from the Paris Agreement's Art. 6.4 mechanism's share of proceeds as well as from voluntary public and private sources. Furthermore, the Fund shall serve the Paris Agreement under the guidance of, and be accountable to, the CMA from 1 January 2019, with a full transition after Art. 6.4 has become operational. ${ }^{43}$

As for the volume of finance, so far, developed countries' contributions do not yet amount to the at least USD 100 billion of climate finance for developing countries per year from 2020 which they had agreed to provide in previous COP decisions. However, several financial announcements were made in Katowice (see below). Furthermore, as mandated in Paris, ${ }^{44}$ at COP24, Parties set up a process starting in 2020 to define a new, increased, collective quantified goal for climate finance from $2025^{45}$.

For the period between 2015 and 2018, the Green Climate Fund has so far only received nearly USD 7 billion of the USD 10.2 billion pledged to it in 2014, caused both by the US's withdrawal from its previous commitments and changes in exchange rates. The first replenishment round of the Fund was launched in October 2018. Germany already pledged EUR 1.5 billion ${ }^{46}$ (USD 1.7 billion $)^{47}$ and Norway USD 516 million to the Fund ${ }^{48}$, both doubling their previous

\footnotetext{
${ }^{41}$ UNFCCC 'Decision 12/CMA.1, Identification of the information to be provided by Parties in accordance with Article 9 , paragraph 5, of the Paris Agreement' UN Doc FCCC/PA/CMA/2018/3/Add.1 (Advance version 19 March 2019)

42 UNFCCC 'Decision 18/CMA.1' (n. 25) section V

43 UNFCCC 'Decision 13/CMA.1 Matters relating to the Adaptation Fund' UN Doc FCCC/PA/CMA/2018/3/Add.2 (Advance version 19 March 2019)

44 UNFCCC 'Decision 1/CP.21' (n. 13) para 53

45 UNFCCC 'Decision 14/CMA.1 Setting a new collective quantified goal on finance in accordance with decision 1/CP.21, paragraph 53' UN Doc FCCC/PA/CMA/2018/3/Add.2 (Advance version 19 March 2019)

${ }^{46} \mathrm{BMZ}$ 'Schulze und Müller in Kattowitz: Deutschland verdoppelt Zusage für internationalen Klimafond'. Press release 03.12.2018 <http://www.bmz.de/de/presse/aktuelleMeldungen/2018/dezember/181203 pm 057 Deutschland-verdoppeltZusage-fuer-internationalen-Klimafonds/index.html> accessed 25 March 2019

${ }^{47}$ Exchange rate used: EUR 1 = USD 1.14 (30 January 2019)

${ }^{48}$ Evans and Timperley, 'COP24: Key outcomes' (n. 11)
} 
contributions. ${ }^{49}$ Japan announced considering raising its contribution after the official start of the replenishment in 2019. Furthermore, more than USD 129 million were pledged to the Adaptation Fund at COP 24, with Germany alone making a contribution of EUR 70 million (USD 80 million).

\section{Loss and Damage}

With the integration of "loss and damage" under Article 8 of the Paris Agreement, the most vulnerable countries had achieved an important step towards the recognition of the fact that there are climate change induced impacts that cannot be adapted to. In Katowice, the key question was in which areas and how the issue of loss and damage should be reflected in the rulebook. Developing countries were pushing to include loss and damage in diverse negotiation areas, with the Transparency Framework, the Global Stocktake and finance being particularly relevant. Developed countries, in contrast, wary about claims for financial compensation, mainly wanted the issue to be subsumed under adaptation.

In the end, Parties were able to find some common ground by including the issue of loss and damage in several sections of the rulebook, including the Transparency Framework and the Global Stocktake..$^{50}$ Despite the rather weak language, this can be considered a significant step forward. The inclusion of loss and damage under the Transparency Framework will allow countries to report on how they have been impacted by climate change in the past, what impacts they expect to be confronted with in the future and how they intend to deal with them, as well as the support needed. With loss and damage also being part of the Global Stocktake, there is now an official process to collect and process this data. This success clearly contrasts with the role of loss and damage in the area of climate finance. Here, there is no explicit reference to this topic, keeping financial support confined to the areas of mitigation and adaptation.

In Katowice, Parties also approved the Report by the Executive Committee of the Warsaw International Mechanism (WIM), the body to address loss and damage associated with impacts of climate change that had been established at the last Polish COP in 2013. After a first review of the mechanism in 2016 in Marrakesh, Parties had agreed on a more rigorous review of the WIM to be undertaken in 2019. Parties and other stakeholders are invited to submit their views and input by 1 February 2019 on possible elements to be included in the review. It remains to be seen whether this review will be able to strengthen the role of the WIM and highlight the relevance of additional support, including in finance, for addressing loss and damage.

\section{The Polish Presidency}

In the run-up to the conference, having Poland as host and president of COP24 had raised numerous concerns as Poland has traditionally often tried to stall progress on climate policy. ${ }^{51}$ Prior to the conference, COP President Kurtyka had advocated for a "realistic" and "pragmatic" approach, criticising calls to have ambition raising as a key issue at the conference, In addition, Poland had adopted special legislation against demonstrations, so it was feared that the country would crack down hard on civil society activism. The latter fears were confirmed when Poland

\footnotetext{
${ }^{49}$ Green Climate Fund 'GCF replenishment wins strong endorsement at COP24' (13 December 2018) <https://www.greenclimate.fund/news/gcf-replenishment-wins-strong-endorsement-at-cop24> accessed 25 March 2019

50 See UNFCCC 'Decision 18/CMA.1, Annex' (n. 25) para 115 and UNFCCC 'Decision 19/CMA.1' (n. 28)

${ }^{51}$ For example, Poland was the only EU member state that vetoed adoption of a long-term low-carbon roadmap in 2012 , see Dave Kearting, 'Poland blocks EU's low-carbon roadmap' (Politico, 10 March 2012) <https://www.politico.eu/article/polandblocks-eus-low-carbon-roadmap/> accessed 25 March 2019
} 
deported or refused entry to a number of civil society activists. Moreover, the Polish government had the conference sponsored by several coal companies and provided ample conference space to the promotion of coal energy.

Nonetheless, the negotiations were ultimately crowned with success (see previous sections). In addition to the core negotiations, the Polish presidency also developed three political declarations ${ }^{52}$ :

- The "Forests for Climate" declaration highlights the importance of conservation and increase of carbon stocks in forests.

- The "Driving Change Together Partnership for Electromobility and Zero Emission Transport" declaration advocates for technological and organisational change towards zero emission transport.

- The "Solidarity and Just Transition Silesia Declaration" highlights the need to ensure a fair and solidarity-based transformation to protect the climate while maintaining economic development and employment.

The three declarations were not adopted by the COP but opened for signature by countries that wanted to support them. Ultimately, each declaration was signed by about 50-60 countries.

The relevance of social impacts of climate policies was highlighted by the "yellow vest" protests that broke out in France just before the COP, triggered by an increase in fuel taxation. The Just Transition Declaration highlights the challenges but also the opportunities connected to the transition. It emphasises the need for inclusive social dialogue and encourages mutual learning and taking just transition issues into consideration in the preparation and implementation of NDCs, adaptation plans and long-term strategies.

\section{Tug Boats - Pioneer Alliances and Non-Party Actors}

The Paris Agreement explicitly acknowledges the role of non-state and subnational actors. And in fact the engagement of non-state and subnational actors has been increasing significantly in recent years. UNEP records that more than 7,000 cities, 245 regions, along with more than 6,000 companies have pledged mitigation action which cover some $17 \%$ of the global population and economic activities accruing at least US $\$ 36$ trillion in revenue. 53

The current contribution to mitigating emissions beyond what countries pledged in their NDCs is limited - some 0.2-0.7 Gt GtCO ${ }_{2}$ e per year by 2030 over fully implemented NDCs and 1.5-2.2 $\mathrm{GtCO}_{2} \mathrm{e}$ per year compared to current policy. The potential impact, however, is considered to be much larger if those initiatives are scaled up across the covered sectors (3.7 - $19 \mathrm{GtCO}_{2} \mathrm{e}$ per year compared to current policy). ${ }^{54}$

\footnotetext{
52 COP24 Presidency, 'Key Initiatives of the Polish Presidency' (n.d.) <https://cop24.gov.pl/presidency/initiatives/> accessed 25 March 2018

53 UNEP, Bridging the Emissions Gap - The Role of Non-State and Subnational Actors (United Nations Environment Programme 2018); UNFCCC, Yearbook of Global Climate Action 2018 (United Nations Framework Convention on Climate Change 2018)

54 ibid UNEP Non-State and Subnational Actors
} 
The key event for non-state and subnational actors in 2018 was, however, not COP24 in Katowice, but the Global Climate Action Summit hosted by California's Governor Jerry Brown in September in San Francisco. More than 4000 representatives from non-state and subnational actors convened, discussed climate action strategies and presented their own commitments. Perhaps the most far reaching announcement of that summit was California's own commitment to achieve fossil free energy supply by the end of 2045. Phasing out fossil fuel consumption for California, a state that would be the fifth largest economy of the world if it was independent and that is not only heavily dependent on fossil fuel consumption but still produces oil and gas, is an extremely ambitious feat.

But non-state and subnational actors continued to receive attention also at COP24, inter alia by participating in the Talanoa Dialogue (see above). A total of 473 submissions were collected, about a third of which originated from subnational governments, private sector organisations or hybrid partnerships and coalitions. ${ }^{55}$ But the COP was also again used as a platform to highlight new commitments by several actors: The World doubled its pledge for climate finance for the time period from between 2021 and 2025 to USD 200 billion, USD 50 billion of which are reserved for adaptation and resilience. Kristalina Georgieva, the Chief Executive Officer of the World Bank, announced that the World Bank will consider climate change in all its work and use a shadow carbon price in its economic valuations. ${ }^{56}$ Also other banks (ING, BBVA, BNP Paribas, Société Générale and Standard Chartered) responsible for EUR 2.4 tn (USD 2.7 tn) of loans declared to steer their lending portfolios towards being compatible with "well below $2^{\circ} \mathrm{C}$ ". Likewise, the European Bank for Reconstruction and Development (EBRD) announced a new energy sector strategy that emphasises the scaling-up of investment in renewables and excludes financing for coal infrastructure, but fails to meet the standards of the World Bank which in a previous announcement had ruled out financing for any upstream fossil fuel investments. ${ }^{57}$

But announcements were not limited to the financial sector. The global shipping giant Maersk pledged to become climate neutral by 2050 and fully transform to carbon neutral fuels and supply chains. To this end the company called for carbon neutral vessels to be commercially viable by 2030. Together with the recent developments at the level of the International Maritime Organization (IMO) there finally seems to be some movement in a sector that has dramatically lagged behind in the recent past. Additionally, the Powering Past Coal Alliance, founded at COP23 and committed to the phase-out of coal, has attracted many new members and now comprises 30 nation states, 22 subnational governments and regions plus 28 business actors. ${ }^{58}$

To conclude, many non-state and subnational actors display a tremendous level of ambition in combatting climate change. This provides an important undercurrent to support global climate action. Not only can non-state actors to some extent make up for the ambition gap that national governments left in their current NDCs. More importantly even, non-state and subnational actors can play an important role in supporting the implementation of the NDCs and creating a sociopolitical environment that can spur ambition in subsequent NDCs.

\footnotetext{
55 UNFCCC 'Updated Overview of inputs into the Talanoa Dialogue' (United Nations Framework Convention on Climate Change, 26 November 2018) <https://talanoadialogue.com/outputs-and-outcome> accessed 25 March 2019

${ }^{56}$ World Bank, 'World Bank Group Announces $\$ 200$ billion over Five Years for Climate Action, Press release' (World Bank, 03.12.2018) <https://www.worldbank.org/en/news/press-release/2018/12/03/world-bank-group-announces-200-billion-overfive-years-for-climate-action> accessed 25 March 2019

57 Evans and Timperley 'COP24: Key outcomes' (n. 11)

58 Powering Past Coal Alliance Declaration <https://www.canada.ca/en/services/environment/weather/climatechange/canadainternational-action/coal-phase-out/alliance-declaration.html> accessed 21 March 2019
} 
But is also important to note that engaging and orchestrating non-state and subnational actors is not a silver bullet. ${ }^{59}$ To realize its full potential, the global action agenda of non-state and subnational actors needs to be integrated more closely with the international negotiations and national policy-making. In Katowice, again the activities from non-state and subnational actors ran mostly in parallel to the intergovernmental negotiations in a separate area of the conference venue. To create positive feedback loops and to bring in the positive momentum from non-state actors more immediate connections need to be built. ${ }^{60}$ For example, the contribution of non-state and subnational actors should be considered systematically in the Global Stocktake. The mandate of the Global Stocktake in principle provides space for this. Another opportunity is to involve them at the national level in participatory process towards developing and updating NDCs. ${ }^{61}$

\section{Lookout - Conclusions and Outlook}

\section{High Expectations, Low Results?}

The assessment of COP24 must necessarily come to a mixed conclusion. On the one hand, the UNFCCC process once more failed to deliver what it set out to deliver, i.e. mobilising action at a scale that is sufficient to prevent dangerous climate change. A strong call for action was missing despite the steady drumbeat of scientific warnings and mounting climate impacts. On the other hand, COP24 delivered a sound technical result with the adoption of the rulebook and thus fulfilled the other half of the expectations.

However, it bears noting that the United Nations are a negotiating platform of sovereign states, not a centralized world government. Negotiators always have to refer back to their national capitals before making any concessions on their positions. International conferences can therefore only rarely take decisions that have not previously been prepared nationally. This is true in particular for the climate regime, which is characterized by the constraint to move forward by consensus. Since 1994 Saudi Arabia has blocked any attempt to agree on Rules of Procedure that include voting by a three-fourths majority if all efforts at reaching consensus have failed. As we have analyzed previously, the climate regime is thus delivering on two important goals, namely providing significance and legitimation for climate policies. It has severe difficulties, however, to reach agreement on the allocation of scarce resources like the atmosphere. ${ }^{62}$

Given recent rollbacks in key countries, in particular the US and Brazil, the adoption of robust implementation guidelines for the Paris Agreement is therefore not a small achievement. It sends a signal that the global community is still able to come to a multilateral agreement on the procedural way forward, and that the vast majority of countries still sees climate change as a major concern. It helped, of course, that the US has a genuine interest in sound rules and thus was rather supportive. China, on the other hand, deviated to some extent from its former position that

\footnotetext{
${ }^{59}$ For a critical assessment of the potential and limits of non-state actors see Sander Chan, Idil Boran, Harro van Asselt, Gabriela lacobuta, Navam Niles, Katharine Rietig, Michelle Scobie, et al. 'Promises and Risks of Nonstate Action in Climate and Sustainability Governance' (2019) Wiley Interdisciplinary Reviews: Climate Change, January, e572

${ }^{60}$ Lukas Hermwille, 'Making Initiatives Resonate: How Can Non-State Initiatives Advance National Contributions under the UNFCCC?' (2018) 18/3 International Environmental Agreements: Politics, Law and Economics 447

${ }^{61}$ Sander Chan, Paula Ellinger and Oscar Widerberg, 'Exploring National and Regional Orchestration of Non-State Action for a $<1.5{ }^{\circ} \mathrm{C}$ World' (2018) 18/1 International Environmental Agreements: Politics, Law and Economics 1

62 Lukas Hermwille, Wolfgang Obergassel, Hermann E. Ott, and Christiane Beuermann 'UNFCCC Before and After Paris What's Necessary for an Effective Climate Regime?' (2015) 17/2 Climate Policy 150
} 
any scrutiny of its performance would amount to a violation of its sovereignty. This is no small step and paves the way for the People's Republic of China to take on a leadership role.

\section{Logbook - Duty for all Seafarers}

In result, the Katowice conference once and for all bridged the traditional bifurcation of "developed" and "developing" countries. Starting in 2024, countries will have to report on their emissions and on their actions according to common rules every two years. For developing countries with limited capacities, the rulebook provides flexibility regarding the scope, frequency, and level of detail of reporting. Countries making use of this option will however need to explain why they require this flexibility and provide self-determined time frames to improve reporting. Additional flexibility applies to LDCs and SIDS.

In return for developing countries agreeing to common rules, developed countries agreed to provide more transparency on climate finance and to start discussions on a new collective finance goal in 2020. Another win for developing countries was the decision that the Kyoto Protocol's Adaptation Fund will in the future serve the Paris Agreement. These institutional decisions were supported by successful replenishment of the GCF and the AF.

The mandate for the implementation and compliance committee is also stronger than may have been expected. While the Paris Agreement explicitly gives only a facilitative role to the committee, it now has a mandate to independently initiate consideration of non-compliance in certain cases. The committee may furthermore on its own consider if a country has not communicated or maintained an NDC, has not submitted its transparency report, or, in the case of a developed country, its indicative finance report.

The negotiation results also provided a solid basis for a Global Stocktake that is successful in catalysing ambition. Parties decided that substantial time will be dedicated to the process. NonParty stakeholders may participate by making submissions and, in principle, in roundtables or workshops. Whether or not the Global Stocktake will become a success will be crucially determined by the way the co-facilitators choose to set up the process.

Finally, the conference failed to adopt decisions on Article 6. This omission weighs heavy considering that Parties may transfer mitigation outcomes under Article 6.2 irrespective of whether or not there is international guidance. This hole in the rulebook should therefore quickly be plugged in order to safeguard the environmental integrity of the Agreement.

\section{Raising Ambition}

Nonetheless, the adoption of the guidelines only prepares the framework for the real work to come, namely real reductions. Only a handful of countries announced in Katowice that they were going to strengthen their contributions, including India, Canada, Ukraine and Jamaica. Germany made a particularly poor showing, having to admit in a stocktake of pre-2020 action that it was going to miss its 2020 emission target by a wide margin. Germany had also contributed to stymying a push by the European Commission to strengthen the EU's 2030 target. Germany could have made a positive contribution by communicating the phase-out plan for coal consumption and production, but the delay of the "coal commission" that was tasked to prepare that plan led to yet another lost opportunity for climate leadership.

With the negotiations on the Paris implementation guidelines (mostly) out of the way, it is now possible to focus on the task of raising ambition. As UN Secretary-General Guterres put it in a statement read out in the COP plenary after the deal had been adopted, "From now on my five 
priorities will be ambition, ambition, ambition, ambition and ambition." 63 To this end, he is convening a special summit on climate change in 2019. This summit and the ongoing process under the UNFCCC will hopefully help to galvanise national discussions on stepping up climate ambition.

Several dozen countries from the "High Ambition Coalition" that had formed at the Paris conference pledged to "step up" their ambition until 2020 by enhancing their NDCs, increasing short-term action, and adoption of long-term low-emission development strategies. ${ }^{64}$ However, it bears noting that the coalition has so far only constituted and re-constituted itself to save the UN climate process. Now that the work of agreeing rules is mostly complete, what is needed is rather an action coalition committed to making actual emission cuts. It would thus make sense to form the High Ambition Coalition into something more stable in order to influence the process throughout the year, not just in the final days of a make-it-or-break-it COP.

COP24 thus has proven that the consensus-based process in the climate regime can deliver common rules for assessing, monitoring and reporting of information. This is no small achievement because a sound information base is indispensible for any serious action. But it remains to be seen whether the Paris Agreement can fulfil the hopes put on it when adopted in Paris - that it is able to engage all countries in a process that leads to reduction of greenhouse gas emissions fast enough to keep the world on a safe path.

\section{Barriers and Prospects for Action}

Arguably, a key factor that has been slowing down climate policy is the power of entrenched interests. Transition research has coined the term "socio-technical regime" to describe the currently dominant way of delivering societal needs such as food, housing, mobility etc. The regime is characterised and stabilised by rules that are cognitive (e.g. belief systems, guiding principles, goals, innovation agendas, problem definitions, search heuristics), regulative (e.g. standards, laws) and normative (e.g. values, roles, behavioural norms) and shared by the relevant actors of a regime (governments, companies, civil society, scientists etc.). Crucially, policymakers and incumbent firms often form a core alliance at the regime level, oriented towards maintaining the status quo. ${ }^{65}$ This mechanism is illustrated for example by the current diesel scandals, where German policymakers are refusing to crack down on German carmakers even though those have fragrantly broken the law.

Transitions may take place when there are instabilities on the regime-level, caused by tensions between the regime and its environment or learning and adaptation processes at the regimelevel itself. These tensions create windows of opportunity for a niche to become more powerful and to replace the "old" regime. "In the end, transitions are structural regime transformations, in which regime actors will ultimately need to change along with the process or fall out of the system". 66

\footnotetext{
63 Karl Mathiesen, Megan Darby and Sara Stefanini, 'Countries breathe life into the Paris climate agreement',(Climate Home News, 15 December 2018) <https://www.climatechangenews.com/2018/12/15/countries-breathe-life-paris-climateagreement/> accessed 25 March 2019

${ }^{64}$ European Commission, 'COP24: EU and allies in breakthrough agreement to step up ambition', (European Commission, 12 December 2018) https://ec.europa.eu/clima/news/cop24-eu-and-allies-breakthrough-agreement-step-ambition_en

${ }^{65}$ Frank W. Geels, 'Regime resistance against low-carbon transitions: introducing politics and power into the multi-level perspective' (2014) Theory, Cult. Soc. 31/5 21

${ }^{66}$ Derk Loorbach, Transition Management: New Mode of Governance for Sustainable Development, PhD Dissertation, Erasmus University Rotterdam (International Books 2007) 294
} 
Factors that may contribute to destabilising the incumbent regime are for example outside events such as climate change impacts, advances in alternative technologies and practices, or internal tensions created by failing to sufficiently deliver on societal needs - such as tackling climate change. Usually, these factors reinforce each other, with increasing viability of alternative solutions making it easier to re-orient policy towards normative pressure. ${ }^{67}$ One may note relevant developments in all of these dimensions.

Climate impacts are being felt all across the globe. While the traditional industrialised countries had long operated under the assumption that climate impacts were mostly an issue for developing countries, events such as the record Central European drought in the summer of 2018 are increasingly dispelling that notion. However, it remains to be seen if and when the mounting impacts will contribute to galvanising action.

Advances in alternative technologies and practices are continuing apace. Renewable wind and solar electricity are increasingly cost competitive not only with new fossil fuel installations but also with old, written-off ones. ${ }^{68}$

Shifts within the regime can be identified in the shifts of international organisations like the World Bank, private finance institutions and global companies like Maersk, as discussed in section VI. In addition, social dissatisfaction with the current pace of climate policy is manifesting itself in developments like the divestment movement or the "school strike for climate" movement that seems to be taken off. Having started with the individual protest of Swedish 16-year-old Greta Thunberg, school strikes have in the meantime spread to a number of countries including Australia, Belgium and Germany. In the USA, the newly emerged "Sunrise Movement" is working to make climate change an urgent priority in the 2020 elections.

Another emerging trend is citizens launching court cases against their governments. The most successful case has so far been the Urgenda case in the Netherlands, which forced the Dutch government to strengthen its climate policy. The case and the debate surrounding it also contributed to the Netherlands emerging as a climate frontrunner, which is now calling on its fellow EU members to strengthen the EU's 2030 emission target from $-40 \%$ to $-55 \%$. Several cases have also been brought against Germany and the European Union, where farmers and others dependent on a sound climate system litigate for stronger climate action.

On the other hand, while some complain about the lack of strong climate policy, others complain about there being too much of it. Two prominent examples in this regard are, first, Donald Trump who campaigned on a platform of reviving the fossil fuel industry, and, second, the "yellow vest" protests in France, which were sparked by carbon taxation.

It is therefore necessary to better take into account the various impacts of climate policies. While there are many synergies with other sustainability goals, such as cleaner air, there are also tradeoffs, such as energy price increases and job losses in emission-intensive industries. Parties should therefore heed the call in the preamble of the Paris Agreement to take into account the imperatives of a just transition. The Polish government usefully highlighted this concern with its promotion of a ministerial just transition declaration. The probably most prominent related

\footnotetext{
${ }^{67}$ Boelie Elzen, Frank W. Geels, Cees Leeuwis and Barbara van Mierlo, 'Normative contestation in transitions in the making: animal welfare concerns and system innovation in pig husbandry' (2011) Res. Policy 40/2 263.

${ }^{68}$ Agora Energiewende and Sandbag, The European Power Sector in 2018. Up-to-date analysis on the electricity transition (Agora Energiewende and Sandbag 2019) <https://sandbag.org.uk/project/power-2018/> accessed 25 March 2019
} 
initiative at national level currently is the "Green New Deal" initiative in the US spearheaded by Representative Ocasio-Cortez.

At the same time, the multiple benefits of ambitious climate policy should be put more into the spotlight. The World Health Organisation reported in Katowice that the health savings alone could compensate more than twice the mitigation costs of achieving the $2^{\circ} \mathrm{C}$ limit.

Another item to consider is that opportunities and barriers vary strongly among sectors. For example, while loss of competitiveness is a strong concern in some energy-intensive industries, it is hardly an issue in other sectors. It is therefore recommendable to focus more on the specific needs of the individual sectors. ${ }^{69}$ Future COPs could contribute to introducing a sectoral perspective to climate policy.

\section{The End of the COP as We Know It?}

With the adoption of comprehensive implementation guidelines for the Paris Agreement, the process of regime building has finally come to an end after decades of negotiations. This raises the question what function the COP may perform in the future. Part of its capacity will be consumed by implementing and overseeing the broad array of mechanisms that have been established, from transparency to finance.

But arguably the main part of the capacity that has now been freed up should be spent focusing on the core task at hand: raising ambition. Future COPs could contribute to this task in a number of ways:

Exchange and mutual learning: The UNFCCC document repository contains a treasure trove of knowledge on climate policy, which has so far hardly been utilised. Countries are required to report on the implementation and expected impact of their national policies in their national communications. Going forward, future COPs could be dedicated to sharing lessons learned and supporting each other in policy implementation.

Broadening outreach: Despite the high public profile of the issue, in national governments climate policy is still often a matter only for the environment ministries and not relevant in the decisions of other ministries. However, the decisions that determine countries' future emission pathways are mostly taken in the energy, transport and other ministries, not in the environment department. The COPs should therefore endeavour to mobilise participation of these ministers in order to discuss how to transform their respective sectors. There might also be a good case for the establishment of a more permanent function of the COP - following to some extent the example of the General Agreement of Tariffs and Trade (GATT) that later became the World Trade Organisation. There, the regular meetings of country representatives were transformed into a standing body that was able to react to the continuing demands for fast reaction and regulation of the world's trade affairs.

To sum up, the Conferences of the Parties should from now on assume less the role of a shipbuilder and instead move to the role of a ship's captain. The boat has been built, equipped with the relevant parts and most of the operational rules for setting the sails. Now is the time to set the course towards an effective protection of our civilization from the risks and dangers of climate change. This demands to foster agreement on the course needed to reach the destination

${ }^{69}$ COP21 RIPPLES Consortium, A Sectoral Perspective to Embark on Transformative Pathways (COP21 RIPPLES Consortium 2018) <https://www.cop21ripples.eu/resources/policy-brief-2/> accessed 25 March 2019 
set out in the Paris Agreement - i.e. to increase ambition and work on a sustainable and just transition. And finally, those members of the crew that want to move faster may decide to build a smaller jollyboat that keeps the Paris Agreement as the platform or "mother ship" but allows for more ambition and may even serve as a tugboat in a calm when the global winds are still. 